$(\mathrm{OR}=0.544,[95 \%$ CI $0.4-0.7] ; \mathrm{p}=0.032)$, which indicates that patients with robust VMP had better neurological outcomes 90 days after discharge.

Conclusion A robust cerebral venous microperfusion profile reflects greater tissue microperfusion, good arterial collateralization status and is associated with improved clinical outcome in patients with AIS.

Disclosures T. Faizy: None. R. Kabiri: None. M. Leipzig: None. S. Christensen: None. G. Broocks: None. F. Flottmann: None. M. Lansberg: None. G. Albers: None. J. Fiehler: None. M. Wintermark: None. J. Heit: None.

\section{0-003 RESULTS OF THE STROKE THROMBOEMBOLISM REGISTRY OF IMAGING AND PATHOLOGY: A MULTICENTER INTERNATIONAL STUDY}

${ }^{1} \mathrm{~W}$ Brinjikji ${ }^{*},{ }^{2} \mathrm{R}$ Nogueira, ${ }^{3} \mathrm{R}$ Hanel, ${ }^{4} \mathrm{~K}$ Layton, ${ }^{5}$ J Delgado, ${ }^{6} \mathrm{M}$ Gounis, ${ }^{7} \mathrm{~A}$ Yoo, ${ }^{8} \mathrm{~V}$ Pereira, ${ }^{9} \mathrm{M}$ Almekhlafi, ${ }^{10} \mathrm{~K}$ Doyle, ${ }^{11} \mathrm{~B}$ Patel, ${ }^{12} \mathrm{~B}$ Jahromi, ${ }^{13} \mathrm{P}$ Kvamme, ${ }^{1} \mathrm{R}$ Kadivel, ${ }^{1} \mathrm{D}$ Dai, 'D Kallmes, 'S Fitzgerald. 'Radiology, Mayo Clinic, Rochester, MN; ${ }^{2}$ Neurology, Grady Memorial Hospital, Atlanta, GA; ${ }^{3}$ Neurosurgery, Baptist, Jacksonville, FL; ${ }^{4}$ Radiology, Baylor Scott White Hospital, Dallas, TX; ${ }^{5}$ Radiology, Abbott Northwestern Hospital, Minneapolis, $M N ;{ }^{6}$ Radiology, University of Massachussets, Worcestire, MA; ${ }^{7}$ Radiology, UT Houston, Houston, $T X_{;}{ }^{8}$ Neurosurgery, University of Toronto, Toronto, ON, CANADA; ${ }^{9}$ Neurology, University of Calgary, Calgary, AB, CANADA; ${ }^{10}$ Physiology, University of Galway, Galway, IRELAND; ${ }^{11}$ Radiology, Carillion Clinic, Carillion, WV; ${ }^{12}$ Neurosurgery, Northwestern Memorial Hospital, Chicago, IL; ${ }^{13}$ Radiology, UT Knoxville, Knoxville, TN

\subsection{6/neurintsurg-2020-SNIS.3}

Background We performed a multicenter prospective clinical registry across 12 centers to study the association between histopathological characteristics of retrieved clots and imaging, stroke etiology and clinical outcomes.

Materials and Methods Following IRB approval at the 12 centers, patients were enrolled in the STRIP registry. All retrieved emboli were sent for histopathological analysis with H\&E and MSB staining. Demographic variables, comorbidities, stroke etiology, imaging findings and procedural details were collected for each case. We studied the association between clot histopathology and imaging findings, stroke etiology and and revascularization outcomes. Student's t-test was used for continuous variables and chi-squared testing for categorical variables.

Results To date, 1457 patients have been included. Platelet rich clots were associated with a significantly lower rate of first pass TICI $2 \mathrm{c} / 3$ revascularization than platelet poor clots $(\mathrm{OR}=0.68,95 \% \mathrm{CI}=0.48-0.88, \mathrm{P}<0.0001)$. The rate of first pass TICI $2 \mathrm{c} / 3$ recanalization was $41 \%$ with aspiration compared to $26 \%$ for stent-triever and $15 \%$ for combined techniques with platelet rich clots $(\mathrm{P}<0.0001)$. There was a significant correlation between platelet rich clots and the absence of hyperdensity on non-contrast CT $(p=0.003)$ and a significant inverse correlation between the percentage of platelets and mean HU on NCCT $(r=-0.243, p=0.005)$. We found that a Hounsfield unit cutoff of 55 or less had a sensitivity and specificity of $70 \%$ for a platelet rich clot. We did not notice any interaction between clot composition and stroke etiology.

Conclusions Interim analysis of the STRIP registry suggests that the platelet content of a clot may be the most revealing factor in determining a clot's imaging features and revascularization outcome. Platelet rich clots are less dense on NCCT and are associated with poorer first pass TICI 2c/3. Aspiration therapy was associated with higher rates of first pass recanalization than stent-retriever thrombectomy or combined techniques.

Disclosures W. Brinjikji: None. R. Nogueira: None. R. Hanel: None. K. Layton: None. J. Delgado: None. M. Gounis: None. A. Yoo: None. V. Pereira: None. M. Almekhlafi: None. K. Doyle: None. B. Patel: None. B. Jahromi: None. P. Kvamme: None. R. Kadirvel: None. D. Dai: None. D. Kallmes: None. S. Fitzgerald: None.

\section{0-004 PROSPECTIVE, MULTI-CENTERED, EMS-ADMINISTERED, PRE-HOSPITAL VALIDATION STUDY OF THE RAPID ARTERIAL OCCLUSION EVALUATION (RACE) SCALE FOR DETECTING LARGE VESSEL OCCLUSION STROKE IN THE UNITED STATES COMPARED TO THE ORIGINAL RACE VALIDATION STUDY FROM SPAIN: A SUBANALYSIS OF THE PREDICT STUDY}

${ }^{1} \mathrm{~A}$ Cruz*, ${ }^{1} \mathrm{E}$ Fortuny, ${ }^{1} \mathrm{~B}$ Ugiliweneza, ${ }^{1} \mathrm{D}$ Wang, ${ }^{2} \mathrm{~A}$ White, ${ }^{1} \mathrm{~N}$ Khattar, ${ }^{1} \mathrm{~S}$ Adams, ${ }^{1} \mathrm{~B}$ Gallinore, ${ }^{1} \mathrm{D}$ Ding, ${ }^{3} \mathrm{~S}$ Wolfe, ${ }^{4} \mathrm{D}$ Heck, ${ }^{1} \mathrm{R}$ James. ${ }^{1}$ Neurosurgery, University of Louisville, Louisville, KY; ${ }^{2}$ Radiology, University of Louisville, Louisville, KY; ${ }^{3}$ Neurosurgery, Wake Forest Baptist Health, Lexington, NC; ${ }^{4}$ Radiology, Forsythe Medical Center, Winston-Salem, NC

\subsection{6/neurintsurg-2020-SNIS.4}

Introduction Pre-hospital identification of patients with large vessel occlusion (LVO) is critical in the timely triage of thrombectomy-eligible LVO patients to comprehensive stroke centers. The Rapid Arterial oCclusion Evaluation (RACE) scale was prospectively validated to identify LVO patients by EMS in Spain and has been widely adopted in the United States, though these healthcare infrastructure and EMS systems may differ significantly and these results may not be completely

Abstract 0-004 Table 1 Sensitivity, Specificity, Accuracy, PPV and NPV values for the RACE scale across various cut-off values for PREDICT (U. $S$ based study) and the Original RACE study (Spain Based) PPV=Positive Predictive Value, Negative Predictive Value

\begin{tabular}{|c|c|c|c|c|c|c|c|c|c|c|}
\hline & \multicolumn{9}{|l|}{ RACE Scale (U.S Based study) } & \multicolumn{4}{|l|}{ RACE scale (Original Spanish Based Study) } \\
\hline $\begin{array}{l}\text { RACE } \\
\text { Score }\end{array}$ & Sensitivity & Specificity & PPV & NPV & Accuracy & Sensitivity & Specificity & PPV & NPV & Accuracy \\
\hline$\geq 1$ & 1.00 & 0.149 & 0.119 & 1.00 & 0.237 & 1.00 & 0.13 & 0.24 & 1.00 & 0.31 \\
\hline$\geq 2$ & 0.958 & 0.303 & 0.137 & 0.984 & 0.371 & 0.97 & 0.27 & 0.27 & 0.97 & 0.42 \\
\hline$\geq 3$ & 0.875 & 0.519 & 0.174 & 0.973 & 0.556 & 0.93 & 0.40 & 0.30 & 0.96 & 0.51 \\
\hline$\geq 4$ & 0.833 & 0.625 & 0.204 & 0.970 & 0.647 & 0.89 & 0.55 & 0.35 & 0.95 & 0.62 \\
\hline$\geq 5$ & 0.792 & 0.716 & 0.244 & 0.968 & 0.724 & 0.85 & 0.68 & 0.42 & 0.94 & 0.72 \\
\hline$\geq 6$ & 0.750 & 0.784 & 0.286 & 0.964 & 0.780 & 0.72 & 0.77 & 0.46 & 0.91 & 0.76 \\
\hline$\geq 7$ & 0.500 & 0.865 & 0.300 & 0.938 & 0.828 & 0.53 & 0.89 & 0.56 & 0.87 & 0.81 \\
\hline$\geq 8$ & 0.250 & 0.947 & 0.353 & 0.916 & 0.875 & 0.32 & 0.95 & 0.65 & 0.84 & 0.82 \\
\hline $\mathbf{9}$ & 0.167 & 0.986 & 0.571 & 0.911 & 0.901 & 0.07 & 0.99 & 0.56 & 0.79 & 0.79 \\
\hline
\end{tabular}

